\section{AB1082 CHARACTERISATION OF A GROUP OF PATIENTS WITH IGG4-RELATED DISEASE: SINGLE CENTRE EXPERIENCE}

A. Kozlova ${ }^{1}$, V. Burlakov², D. Abramov², A. Laberko², G. Sagoyan²,

A. Shcherbina ${ }^{2}{ }^{1}$ Immunology, National Medical Research Center of Pediatric Hematology, Oncology and Immunology named after Dmitry Rogachev Moscow, Russia; ${ }^{2}$ Immunology, National Medical Research Center of Pediatric Hematology, Oncology and Immunology named after Dmitry Rogachev Moscow, Russia, Moscow, Russian Federation

Background: Immunoglobulin G4-related disease (IgG4-RD) is a chronic systemic inflammatory condition with an unclear pathophysiology and lgG4-positive plasma cells infiltration of various organs and parts of the body. If untreated, the disease can lead to fibrosis and irreversible organ damage. IgG4-RD mostly has been described in adults, hence it is generally unknown among paediatricians. Objectives: We conducted a retrospective analysis of clinical features and response to therapy of five patients (one female, four males, median age 13,6 years) with IgG4-related disease, treated in our Centre.

Methods: The diagnosis was confirmed by detection of lymphoplasmacytoid infiltration with $>30 \%$ of cells expressing IgG4 in all, and elevated IgG4 serum concentration in 4 cases.

Results: Three patients had localised lesions (orbit, hip muscle, peripancreatic tissue, respectively), two - multi-organ disease with polylymphadenopathy, pulmonary, renal and hepatic foci, dacryoadenitis with oedema of the eyelids. Autoimmune thrombocytopenia $\left(70 \times 10^{9} /\right)$, neutropenia $\left(0,79 \times 10^{9} / \mathrm{l}\right)$ were present in one patient. Rituximab therapy was successful in 2 cases (one patient received monotherapy with rituximab, another one - Rituximab and Sirolimus). Two other patients received JAK inhibitor therapy (ruxolitinib) with good effect. No side effects were noted. One patient underwent surgery - the infiltration in the abdominal cavity was removed with positive effect without specific therapy.

Conclusions: IgG4-RD symptoms can be diverse and sometimes atypical, so dealing with this pathology requires physician's awareness. Rituximab was effective in patients with multi-organ manifestations, and JAK inhibitor (Ruxolitinib) was effective in patients with mono-focal disease. Steroids are routinely used in IgG4$\mathrm{RD}$ as a first line of treatment with significant side effects. We propose that alternative drugs could be used in IgG4-RD, especially in paediatric patients to achieve fast remission with significant morbidity.

Disclosure of Interest: None declared

DOI: 10.1136/annrheumdis-2018-eular.5673

\section{AB1083 CLINICAL AND DENSITOMETRIC CHARACTERISTICS IN PAEDIATRIC POPULATION WITH RISK FACTORS TO DEVELOP LOW BONE MASS/OSTEOPOROSIS}

B. Magallares López ${ }^{1}$, J. Betancourt ${ }^{1}$, G. Fraga ${ }^{1}$, E. Quesada-Masachs² ${ }^{2}$, M. López - Corbeto ${ }^{2}$, M. Torrent ${ }^{1}$, A. Marin ${ }^{1}$, S. Herrera ${ }^{1}$, E. Carreras ${ }^{1}$, J. Casademont ${ }^{1}$, H. Corominas ${ }^{1}$, J. Malouf ${ }^{1}{ }^{1}$ Santa Creu i Sant Pau Hospital; ${ }^{2}$ Vall d'Hebron Hospital, Barcelona, Spain

Background: Low Bone Mass (LBM)/Paediatric Osteoporosis (Ped OP) is a disorder of unknown prevalence, partly due to the lack of diagnosis, associated with the absence of clinical manifestations of the disease until patients develop complications such as fractures, deformities or pain

Objectives: To describe the clinical and densitometric characteristics of the paediatric population with risk factors to develop LBM/Ped OP

Abstract AB1083 - Table 1

\begin{tabular}{lcccc}
\hline Age group & $\begin{array}{c}\mathrm{N}, \% \text { age } \\
\text { group }\end{array}$ & $\begin{array}{c}\text { Average calcium } \\
\text { intake }(\mathrm{mg} / \mathrm{d}) \pm \mathrm{SD}\end{array}$ & $\begin{array}{c}\text { Recommended Daily } \\
\text { Amount }(\mathrm{RDA})(\mathrm{mg} / \mathrm{d})\end{array}$ & $\begin{array}{c}\% \text { that } \\
\text { reach RDA }\end{array}$ \\
\hline $\begin{array}{l}\text { Preescholar } \\
(2-3 \mathrm{y})\end{array}$ & $8,8.9 \%$ & $847 \pm 271$ & 700 & $50 \%$ \\
$\begin{array}{l}\text { Scholar age } \\
(4-9 \text { y) }\end{array}$ & $\begin{array}{c}29, \\
32.2 \%\end{array}$ & $671 \pm 238$ & 1000 & $27.6 \%$ \\
$\begin{array}{l}\text { Teenagers } \\
(10-17 \mathrm{y})\end{array}$ & $\begin{array}{c}52.2 \% \\
\text { Young }(18-\end{array}$ & $660 \pm 348$ & 1300 & $8.7 \%$ \\
20 y) & $6,6.7 \%$ & $726 \pm 156$ & 1100 & $0 \%$ \\
\hline
\end{tabular}

Methods: We collected prospectively demographic and clinical data of patients aged 2 to 20 years, referred for bone health assessment due to the presence of risk factors for LBM/Ped OP, including: inflammatory diseases, immunosuppressants and/or corticosteroids, malabsorptive diseases and chronic systemic disorders. We evaluated daily calcium intake and Bone Densitometry (DXA) was performed. We did also a vertebral morphometry

Results: Data were collected from 90 patients, with an average age of 9'9 years, $53 \%$ female, $82 \%$ Caucasian. The age distribution and calcium intake by age can be seen in table 1 .

There was a significant decrease in the compliance of the RDA with calcium with increasing age $(p=0.01)$. No differences were found in the average daily calcium intake between the different diagnostic groups.

The most frequent diagnoses were: Malabsorption:44.4\%, JIA:20\%, Nephropathies: $17.8 \%$, Haematological diseases: $7.8 \%$ and Vasculitis: $4.4 \%$

$18 \%$ of the sample had had a fracture (Fx), $44 \%$ of them had more than one, being the adolescents the group of greater prevalence. 3 cases met the criteria for fragility Fx (vertebral Fx).

$20 \%$ of the patients were on systemic corticosteroids, with an average dose of $5.9 \mathrm{mg}$ of prednisone (or equivalent)/day, and another $20 \%$ had previously received them. The total cumulative average corticosteroid dose in both groups was: 7 grams of prednisone, with an average exposure of 37 months. 29 patients $(32 \%)$ received immunosuppressive treatment, of which $20 \%$ were methotrexate (alone or in combination with biological DMARD).

Only $7 \%$ had supplements with Calcium and $14 \%$ with Vitamin D.

$100 \%$ had a normal calcium, $82 \%$ a normal phosphate (rest slightly increased) and $11 \%$ were deficient in Vitamin D

$13 \%$ of the sample had a LBM for their age assessed by DXA. The densitometric results can be seen in Table 2 .

Abstract AB1083 - Table 2

\begin{tabular}{lccc}
\hline DXA results & Max & Min & \% with Z score $\leq-2$ \\
& Z score & Z score & \\
\hline Vertebral Z score & -3 & 2 & $13.3 \%$ \\
Whole body Z score & -3 & 1.8 & $9.2 \%$ \\
Total femoral Z score & -4.8 & 2.3 & $10.7 \%$ \\
Femoral neck Z score & $-4,8$ & 3 & $12 \%$ \\
\hline
\end{tabular}

Conclusions: Calcium intake in children and young with at least 1 risk factor for LBM/Ped Op is lower than recommended, especially in the groups with the highest requirements.

Up to $13 \%$ of this population have a BMO for their age and a $3{ }^{\prime} 3 \%$ meets Ped OP criteria.

Larger studies are needed to help us to identify paediatric patients who are candidates for bone health screening

Disclosure of Interest: None declared

DOI: 10.1136/annrheumdis-2018-eular.3011

\section{$\mathrm{AB} 1084$ \\ PRELIMINARY RESULTS OF THE USE OF SERUM CALPROTECTIN (MPR8/MPR14) IN CLINICAL PRACTICE IN PAEDIATRIC RHEUMATOLOGY}

B. Magallares López ${ }^{1}$, L. Martínez-Martínez², M.C. Hernandez Lafuente², E. Molto Lacosta $^{2}$, Y. Alvaro Gargallo ${ }^{2}$, H.S. Park ${ }^{1}$, I. Castellví ${ }^{1}$, M. Millán Arciniegas ${ }^{1}$,

C. Díaz-Torné ${ }^{1}$, P. Moya ${ }^{1}$, A. Laiz ${ }^{1}$, J. Casademont ${ }^{3}$, H. Corominas ${ }^{1}$, E. Carreras ${ }^{4}$, C. Juarez ${ }^{2} .{ }^{1}$ Rheumatology, ${ }^{2}$ Immunology; ${ }^{3}$ Internal Medicine; ${ }^{4}$ Pediatrics, Santa Creu i Sant Pau Hospital, Barcelona, Spain

Background: Serum Calprotectin is a new biomarker of clinical activity in Rheu matology, especially in Juvenile Idiopathic Arthritis (JIA)

Objectives: To assess the use of serum Calprotectin in paediatric patients with inflammatory/Rheumatic diseases in clinical practice

Methods: We retrospectively collected Demographic and Clinical data from patients of our Paediatric Rheumatology Clinic, in which serum Calprotectin levels were determined.

The determination of serum Calprotectin was carried out using the ELISA technique.

Diagnostic and Inflammatory activity data were also collected: RCP, ESR and Clinical Assessment of the patients

Results: We present 28 patients, $61 \%$ females, with an average age of 11 (3-23 years)

The diagnoses were as follows: 16 JIA (57\% of the total), of which 8 were of the Oligoarticular type, 3 were Polyarticular, 3 were Arthritis related to Enthesitis, 1 was Psoriatic and 1 Systemic. Other diagnoses were: Behçet, ${ }^{1}$ Autoinflammatory Diseases: 4 (2 ADA2 Deficit, 1 Familial Mediterranean Fever, 1 PFAPA) and 7 patients had suspected rheumatological/inflammatory diseases in study 17 patients were considered clinically inactive, 6 with inflammatory activity and 3 doubtful at the time of blood test. The mean values of Calprotectin, RCP and ESR can be seen in Table 1. 
Abstract AB1084 - Table 1

\begin{tabular}{lccc}
\hline & $\begin{array}{c}\text { Calprotectin }(\mu \mathrm{g} / \mathrm{mL}) \\
\text { (range) }\end{array}$ & $\begin{array}{c}\text { PCR }(\mathrm{mg} / \mathrm{dL}) \\
\text { (range) }\end{array}$ & $\begin{array}{c}\text { ESR }(\mathrm{mmHg}) \\
\text { (range) }\end{array}$ \\
\hline Active & $3,43^{1,80-5,31}$ & $4,27(0,7-11,6)$ & $16,86^{3-51}$ \\
Inactive & $2,15(0,78-4,06)$ & $1,83(0,7-4,6)$ & $13,11^{3-43}$ \\
\hline
\end{tabular}

Calprotectin was statistically correlated with Clinical Activity $(p=0.018)$, however, neither ESR ( $p=0.539)$ nor RCP $(p=0.059)$ did, although in RCP there was a clinical trend, (ANOVA)

Calprotectin, RCP and ESR were negative in $91 \%, 80 \%$ and $76 \%$ respectively of Inactive patients; and positive in $43 \%, 100 \%$ and $33 \%$ of the Active ones

The analysis of the ROC curves in our sample showed that the value that allows to discriminate between active and non-active disease with a Sensitivity of $80 \%$ and a Specificity of $69 \%$ is $2 ' 07 \mu \mathrm{g} / \mathrm{mL}$

Serum Calprotectin was 2 points higher in the group of patients with Autoinflammatory diseases than in the group of JIA, with a mean of 4.91 compared to 2.90 $(p=0.002)$. However, since it is a retrospective study, we must bear in mind that this can be influenced by the reasons for the test request, being in the group of Autoinflammatory Disease the suspicion of active disease, and in the AIJ simply monitoring or assessment of treatment optimisation.

It should be noted that, in the patients in diagnostic process that did not present any rheumatological disease (final diagnoses of: arthralgias in 3 cases and glomerulonephritis not associated to rheumatologic/autoimmune disease in 1), serum Calprotectine did not exceed in any case the $1.15 \mu \mathrm{g} / \mathrm{mL}$

Conclusions: Serum Calprotectin is emerging as a useful marker, not only in the field of JIA, but also in other diagnostic groups such as Autoinflammatory Diseases.

Prospective and larger studies are needed to determine its role

Disclosure of Interest: None declared

DOI: 10.1136/annrheumdis-2018-eular.3529

\section{AB1085 THE FACTORS AFFECTING REMISSION IN JIA PATIENTS, SINGLE CENTRE RESULTS}

B. Sozeri ${ }^{1}$, T. Demircan Bilen ${ }^{1}$, D. Kurtulus ${ }^{2}$, I. Islek ${ }^{1} .{ }^{1}$ Pediatric Rheumatology; ${ }^{2}$ Physical Medicine and Rehabilitation, University of Health Sciences, Istanbul, Umraniye Training and Research Hospital, Istanbul, Turkey

Background: Juvenile idiopathic arthritis (JIA) is the most common rheumatic disease in childhood. Nowadays, in the management of JIA, clinical remission is the accepted goal. However, remission is much associated with the JIA subtype and inversely with suggested predictors for poor outcome.

Objectives: The aim of the study is to evaluate the predictors of clinical outcome in patients with juvenile idiopathic arthritis

Methods: This was a single-centre, an observational study including children diagnosed with JIA at Health Sciences University Istanbul, Umraniye Education and Research Hospital, Turkey, between June 2016 and January 2018. All patients were evaluated at the time of diagnosis, and at 3 months of their disease. We routinely collected the patients' baseline profile which included the age of disease onset, gender, number of active joints, patients'and physicians'global assessment of disease activity (PGA, range from 0 to $10 \mathrm{~mm}$; 0 is the best score), the JADAS 27 score. and therapy. Patients were identified through the divisional database which includes all patients seen in the rheumatology clinic.

Results: A total of $141 \mathrm{JIA}$ patients were included in the analysis. The mean follow-up duration of these patients was 23.36 months (range from 12 to 156 months). We examined 71 joints in all patients. At the time of diagnosis, it was seen that they were frequently in knee joint $(61.7 \%)$ and sacroiliac joints (34.8\%). The rate of improvement of joints in the last visit was found to be metatarsophalangeal joints (100\%), sacroiliac joints (79\%) and knee joints (44.8\%), respectively. The non-systemic group $(n=133)$ was evaluated for initial steroid use, among the patients, $54(\% 41)$ had steroid therapy at the time of diagnosis. There was seen that 29 of the 141 patients $(20.6 \%)$ were in the remission in 3 months of follow-up. According to subtype of JIA patients, systemic patients (62.5\%) were frequently in remission at 3 months. At the end of the study, of the 141 patients, $72(51.1 \%)$ achieved remission and were assigned to the remission group. Among the patients in the remission group, $44(49.4 \%)$ had episodes of disease flares. The other $30(40.5 \%)$ patients did not have disease flares. Comparing the baseline data in the remission group and non-remission group, there was no difference between these two groups in disease onset age, gender, JIA subtypes, number of active joints at disease onset and JADAS 27 scores and used steroid therapy. We also analysed whether each group used biological drugs and analysed the duration of starting biologic therapy. Among 72 patients achieved remission, 17 $(23.6 \%)$ patients had at least one biological drug. There was no difference between two groups. The median time of biologic drug starting was 12 (interquartile range (IQR), 12) months. There was longer time of biologic drug starting in non-remission group than remission group (32.3 \pm 36.2 vs $25.0 \pm 31.4, p>0,05)$. We determine that in systemic and poli JIA patients who were used biological therapy were found to have a high percentage of achieved to remission

Conclusions: JIA is a heterogeneous disease with significant variability in course and long-term outcome. No parameter could be used as a single predictor of long term outcomes. Standardised baseline work-up, disease activity evaluation and a definition of a treat to target approach will result in better health outcomes for JIA patients

Disclosure of Interest: None declared

DOI: 10.1136/annrheumdis-2018-eular.4234

\section{AB1086 A 6-MONTH, MULTICENTER, OPEN-LABEL, EXPLORATORY STUDY OF FIXED DOSE NAPROXEN/ ESOMEPRAZOLE IN ADOLESCENT PATIENTS WITH JUVENILE IDIOPATHIC ARTHRITIS (JIA)}

D.J. Lovell ${ }^{1}$, J.A. Dare ${ }^{2}$, J. Ball ${ }^{3}$, M. Francis-Sedlak ${ }^{3}$, B.D. LaMoreaux ${ }^{3}$, R.J. Holt ${ }^{3,4}$ ${ }^{1}$ Cincinnati Children's Hospital Medical Center, Cincinnati; ${ }^{2}$ Arkansas Children's Hospital, Little Rock; ${ }^{3}$ Horizon Pharma USA, Inc., Lake Forest, ${ }^{4}$ University of Illinois-Chicago, College of Pharmacy, Chicago, USA

Background: JIA is an inflammatory arthritis of unknown etiology, which lasts for greater than 6 weeks with onset before 16 years of age. ${ }^{12}$ Per the ACR guidelines, JIA is the most common chronic rheumatic disease in children. ${ }^{3}$ NSAIDs have been the mainstay of initial management with naproxen being commonly used, but they can cause serious side effects such as gastritis. Herein, we report the results of a clinical trial in JIA patients receiving one of 3 fixed doses of naproxen/esomeprazole magnesium (nap/eso) given BID (table 1).

Objectives: To evaluate the signs/symptoms of JIA, safety and tolerability of nap/ eso in adolescents age 12 to 16 years.

Methods: Forty-six children and adolescents with JIA by ILAR criteria, mean age of 13.6 years, from 18 US sites were prospectively enrolled over 2 years and treated for up to 6 months. Mean number of active joints at baseline was 3.1 Doses were based on baseline weight (table 1). Disease activity was assessed with the ACR Pediatric-30,-50,-70,-90 Response and the Childhood Health Assessment Questionnaire (CHAQ) discomfort and functional scores at months 1,3 , and 6 as change from baseline. Occurrence and causality were assessed for treatment emergent AEs (TEAEs) and discontinuations were monitored monthly. Results: Forty-six patients received at least 1 dose of study drug and $36 \mathrm{com}$ pleted the trial. The\% of patients achieving ACR Paediatric response increased over time (figure 1). CHAQ discomfort improved at each assessment and func tional scores improved at all assessments for 'Arising, Walking, and Activities' with several improved for 'Dressing and Grooming, Eating, Hygiene, and Grip'. There was no indication of a dose-related efficacy effect. Thirty-seven (80.4\%) had at least 1 TEAE. Frequent TEAEs $(\geq 5 \%)$ were upper respiratory tract infection, upper abdominal pain, sinusitis, diarrhoea, headache, nausea, and ligament sprain. Eleven $(23.9 \%)$ had at least 1 TEAE considered to be related to study drug. Most frequent study drug-related TEAE ( $\geq 5 \%$ ) was upper abdominal pain Four $(8.7 \%)$ discontinued due to a TEAE.

Abstract AB1086 - Table 1. Minimum and Maximum Study Drug Dose (nap/eso) by Weight Group

\begin{tabular}{lrr}
\hline Weight at Enrollment $\mathbf{( k g})^{1}$ & Minimum Dose $^{2}$ & Maximum dose $^{2}$ \\
\hline$<38$ & $250 \mathrm{mg} / 20 \mathrm{mg}$ & $250 \mathrm{mg} / 20 \mathrm{mg}$ \\
$38-<50$ & $250 \mathrm{mg} / 20 \mathrm{mg}$ & $375 \mathrm{mg} / 20 \mathrm{mg}$ \\
$50-<75$ & $375 \mathrm{mg} / 20 \mathrm{mg}$ & $500 \mathrm{mg} / 20 \mathrm{mg}$ \\
$\geq 75$ & $500 \mathrm{mg} / 20 \mathrm{mg}$ & $500 \mathrm{mg} / 20 \mathrm{mg}$
\end{tabular}

${ }^{1}$ Based on typical day-to-day fluctuations in body weight, a $\pm 3 \%$ window was permitted and used at the discretion of the Investigator when assigning the initial dose group. ${ }^{2}$ Study drug dose, given twice daily. 


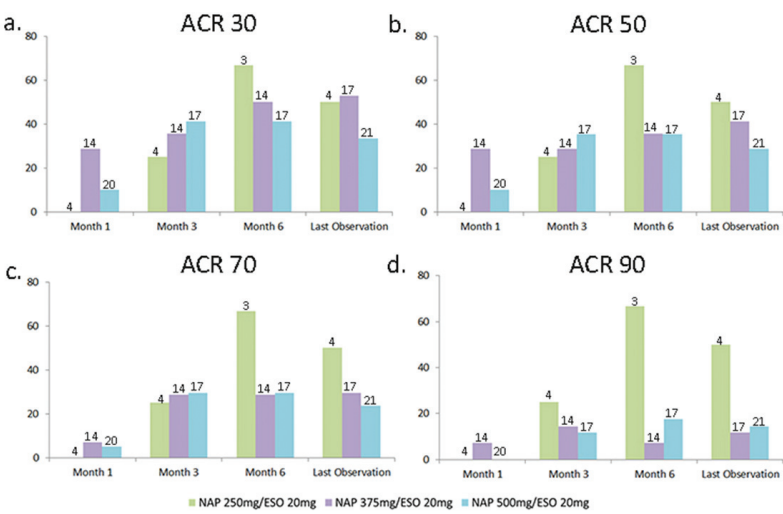

Abstract AB1086 - Figure 1

Note: the number above each bar represents the number of patients at that dose. The ACR Pediatric-30,-50, -70 , and -90 responses were defined as an improvement of at least $30 \%$ (or $50 \%, 70 \%, 90 \%$ respectively) from baseline in at least 3 of the 6 signs and symptoms variables, with no more than 1 of the remaining variables worsening by $>30 \%$. JIA signs and symptoms variables: physician's global assessment of disease activity, CHAQ disability index score, CHAQ global assessment of well-being, number of joints with active arthritis, number of joints with limited range of motion, serum CRP or ESR.

Conclusions: Improvement in JIA signs and symptoms occurred at most assessments and by month 6, the percentage of patients with an ACR Pediatric-30,$50,-70$, and -90 Response was $47.1 \%, 38.2 \%, 32.4 \%$, and $17.6 \%$. No new safety signals were identified for the well-characterised components of this fixed dosed JIA treatment, which was developed to reduce the risk of gastric ulcers.

\section{REFERENCES:}

[1] Petty RE, et al. J Rheumatol 2004:31:390-392

[2] Rigante D, et al. Clinic Rev Allerg Immunol 2015; 49:253-261

[3] Ringold S, et al. Arthritis Rheum 2013; 65 (10):2499-2512

Disclosure of Interest: D. Lovell Grant/research support from: National Institutes of Health, NIAMS. Cincinnati Childrens Hospital Medical Centre receives funds from AstraZeneca, Bristol-Myers Squibb, AbbVie, Pfizer, Roche, Novartis, UBC, Forest Research Institute, Horizon Pharma, Johnson and Johnson, Biogen, Takeda, Genentech, GlaxoSmithKline, Boehringer Ingelheim, Celgene, and Janssen for consulting, Speakers bureau: Genentech and Bristol Meyers Squibb, J. Dare Grant/research support from: AbbVie, AstraZeneca, Bristol-Myers Squibb, Horizon Pharma, Medac, Pfizer, Roche and UCB, J. Ball Shareholder of: Horizon Pharma USA, Inc., Employee of: Horizon Pharma USA, Inc., M. Francis-Sedlak Shareholder of: Horizon Pharma USA, Inc., Employee of: Horizon Pharma USA, Inc., B. LaMoreaux Shareholder of: Horizon Pharma USA, Inc., Employee of: Horizon Pharma USA, Inc., R. Holt Shareholder of: Horizon Pharma USA, Inc., Employee of: Horizon Pharma USA, Inc.

DOI: 10.1136/annrheumdis-2018-eular.1089

\section{AB1087 PROLONGED RESPONSE WITH TUMOUR NECROSIS FACTOR ALFA INHIBITION IN A 5 YEAR OLD BOY WITH SEVERE MANIFESTATIONS OF IL-36 RECEPTOR ANTAGONIST DEFICIENCY (DITRA)}

D. Clemente ${ }^{1}$, J.C. López Robledillo ${ }^{1}$, A. Torrelo ${ }^{2}$, A. Hernández ${ }^{2}$, E. Villalobos ${ }^{3}$. ${ }^{1}$ Pediatric Rheumatology Unit, ${ }^{2}$ Pediatric Dermatology, ${ }^{3}$ Pediatrics, Hospital Niño Jesús, Madrid, Spain

Background: Deficiency of the interleukin (IL) - 36 receptor antagonist (DITRA) is an autosomal recessive autoinflammatory syndrome caused by mutations in the IL36RN gene. Clinical manifestations of DITRA include recurrent episodes of generalised skin postulation, fever, systemic inflammation and leukocytosis. An uniformly effective treatment for DITRA has not yet been identified.

Objectives: We present a case of a 5 year old patient with DITRA with prolonged response with tumour necrosis factor alfa inhibition with adalimumab.

Methods: A five-year-old came to our dermatology clinic after worsening of a previous diagnosed plaque psoriasis, with an erythematous scaly dermatitis that extended throughout the trunk. Treatment with acitretin and cyclosporin were not effective and patient developed in few weeks a generalised erythroderma with pustules covering almost every part of his body, including palms and soles. He was admitted for the onset of fever and irritability due to painful rubbing of the skin. Family history of recurrent fevers or psoriasis were not revealed. Parents were not consanguineous.

Complete blood count showed leukocytosis with neutrophilia and thrombocytosis with an erythrocyte sedimentation rate (ESR) of $6 \mathrm{~mm} / \mathrm{hr}$ and a C-reactive protein (CRP) of $8,4 \mathrm{mg} / \mathrm{dl}$. Biochemistry panel revealed a mild elevation of liver enzymes without other abnormalities. Antinuclear antibody (ANA) and rheumatoid factor were negative with normal serum immunoglobulin and complement. Blood culture grew E. Coli, S. Maltophila and S. epidermidis. Skin biopsy showed acanthosis and papillomatosis with perivascular polymorphous inflammatory cells. Genetic analyses showed a homozygous mutation in the IL36RN gene (pSer113Leu). No mutations were detected in IL1RN and CARD 14 genes.

Results: Treatment was initiated with intravenous methylprednisolone $2 \mathrm{mg} / \mathrm{kg} /$ day and subcutaneous anakinra $2 \mathrm{mg} / \mathrm{kg} /$ day. Cefotaxime and co-trimoxazole were added until blood cultures were negative. Although skins lesions improved during the following days and patient was finally discharged, symptoms reappeared when decreasing the steroid dose. Three months later adalimumab and methotrexate were started, allowing the patient to end treatment with corticoids without evidence of activity of the disease.

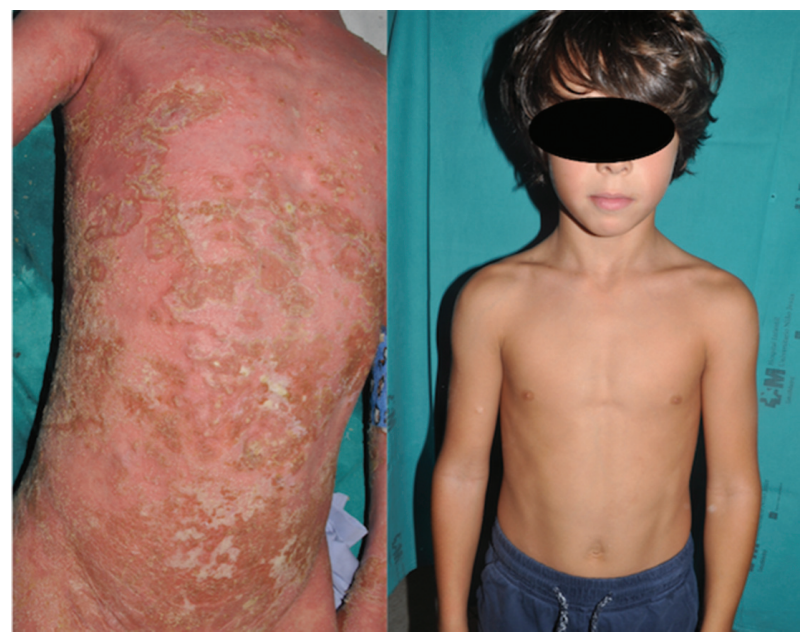

Abstract AB1087 - Figure 1

Conclusions: After incomplete response with anakinra, inhibition of tumour necrosis factor alfa resulted in a prolonged response in our patient with deficiency of the interleukin (IL)-36 receptor antagonist (DITRA).

Disclosure of Interest: None declared

DOI: 10.1136/annrheumdis-2018-eular.6532

\section{AB1088 CAPILLARY HEMOSIDERIN DEPOSITS OR EXTRAVASATIONS: A SUBTYPE OF HAEMORRHAGETHAT ACQUIRES SEPARATE ATTENTION IN QUANTITATIVE ANALYSIS OF NAILFOLD CAPILLAROSCOPY IN CHILDHOOD-ONSET SLE}

D. Schonenberg-Meinema ${ }^{1}$, M. van den Berg ${ }^{1}$, A. Nassar-Sheikh-Rashid ${ }^{1}$, M. Boumans ${ }^{2}$, M. Cutolo ${ }^{3}$, T. Kuijpers ${ }^{1}$, V. Smith ${ }^{4}$, on behalf of EULAR study group on microcirculation in rheumatic diseases. ${ }^{1}$ Pediatric Hematology, Immunology, Rheumatology and Infectious diseases, Emma Childrens Hospital, Academical Medical Center (AMC); ${ }^{2}$ Department of Clinical Immunology and Rheumatology, Academical Medical Center (AMC), Amsterdam, Netherlands; ${ }^{3}$ Research Laboratory and Academic Unit of Clinical Rheumatology, University of Genova, Genova, Italy; ${ }^{4}$ Department of Rheumatology, Ghent University Hospital, Ghent, Belgium

Background: Quality of images in nailfold capillaroscopy has improved in the last years by introduction of videocapillaroscopy. Microangiopathy, as observed in capillaroscopy of SLE-patients, ${ }^{1-3}$ can now be described by more detailed quantitative analysis. Recently, in a small cohort $(n=22)$ of childhood-onset SLE (cSLE), we described capillary bleedings by two different subtypes: large haemorrhages and small point-shaped haemorrhages with a total count of resp. 0.2/1.5 per 
analysed image per patient. ${ }^{4}$ These small point shaped haemorrhages have also been described as hemosiderin deposits. ${ }^{5}$

Objectives: To describe the reliability of assessment of two subtypes in capillary haemorrhages by inter-observer agreement.

Methods: Three observers, DS (paediatric rheumatologist with experience in capillaroscopy), AN (fellow paediatric rheumatology without experience in capillaroscopy) and MB (trainee in adult rheumatology with experience in capillaroscopy), scored capillaroscopy images from patients with Raynaud's phenomenon and with cSLE. The observers were blinded for patient name and diagnosis. The number of haemorrhages were scored per subtype. Hemosiderin deposits were defined as small point-shaped extravasations surrounding the capillary apex (see image). Large haemorrhages were defined according to the Atlas of Capillaroscopy. ${ }^{6}$ Reliability was calculated by the intra-class correlation coefficient (ICC) with $95 \%$ confidence interval $(\mathrm{Cl})$. Statistical analyses was performed by IBM SPSS Statistics version 24

Results: Two-hundred images from 50 patients (diagnosed with Raynaud's phenomenon and/or CSLE) were scored by the three independent observers. ICC for the number of capillaries with hemosiderin deposits was $0.77(95 \% \mathrm{Cl} 0.69-0.82)$. ICC for the number of large capillary haemorrhages was 0.97 (95\% $\mathrm{Cl} 0.96-0.98)$.

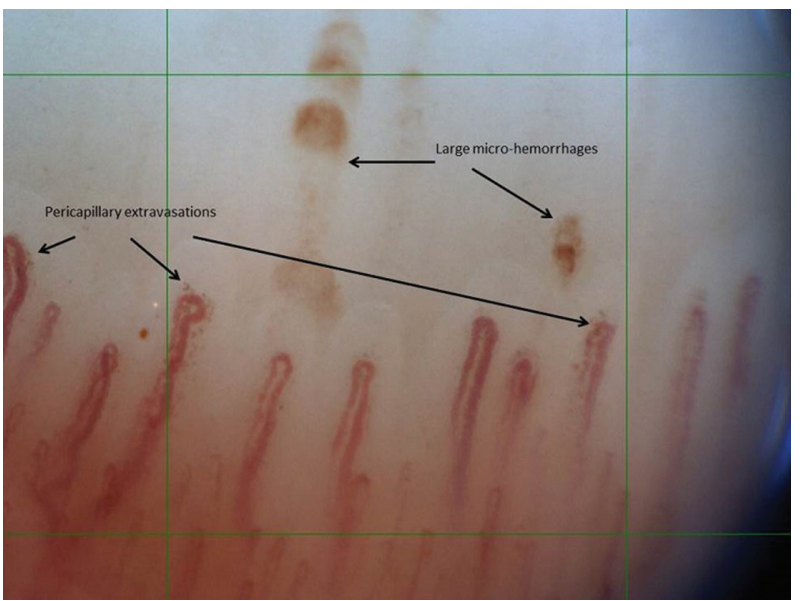

Abstract AB1088 - Figure 1

Conclusions: Reliability of the observation 'hemosiderin deposits' in nailfold videocapillaroscopy was good with an ICC of 0.77 . This study shows that capillary haemorrhages can be described in 2 subtypes: 'large haemorrhages' and 'hemosiderin deposits' which are small point-shaped extravasations surrounding the capillary apex.

\section{REFERENCES:}

[1] Ingegnoli F, Herrick AL. Nailfold capillaroscopy in pediatrics. Arthritis Care \& Research 2013;65(9): 1393-1400.

[2] Ingegnoli F, Zeni S, Gerloni V, Fantani F. Capillaroscopic observations in childhood onset rheumatic diseases and healthy controls. Clinical and experimental rheumatology 2005;23(6): 905-911.

[3] Piotto DGP, Len CA, Hilario MOE, Terreri MTRA. Nailfold capillaroscopy in children and adolescents with rheumatic diseases. Rev Bras Reumatol 2012;52(5):722-732

[4] Schonenberg-Meinema D, van den Berg JM, Nassar-Sheikh-Rashid A, de Bree GJ, Hak AE, van Onna M, Melsen K, Cutolo M, Kuijpers TW, Smith V. Capillaroscopy findings in childhood-onset systemic lupus erythematosus, a Dutch experience of 20 children and adolescents. EULAR 2017, poster 4704

[5] Meroni M, Pizzorni C, Sulli A, Rossi P, Stobbione P, Cutolo M. Selected nailfold videocapillaroscopy changes are linked to SLE-onet in a cohort of UCTD subjects. ACR 2017, poster 698.

[6] Cutolo M. Atlas of capillaroscopy in rheumatic diseases. Milan: Elsevier;2010.

Disclosure of Interest: None declared

DOI: 10.1136/annrheumdis-2018-eular.1901

\section{AB1089}

INVESTIGATION OF THE EFFICACY AND SAFETY OF SECUKINUMAB TREATMENT IN JUVENILE IDIOPATHIC ARTHRITIS SUBTYPES OF JUVENILE PSORIATIC AND ENTHESITIS-RELATED ARTHRITIS: DESIGN OF A RANDOMISED, DOUBLE-BLIND, PLACEBO CONTROLLED, MULTICENTER STUDY

D. Foell ${ }^{1}$, J.A. Veit ${ }^{2}$, E. Ilsley ${ }^{3}$, K. Abrams ${ }^{4}$, on behalf of CAIN457F2304 Study Group. ${ }^{1}$ Klinik für Pädiatrische Rheumatologie und Immunologie,

Universitätsklinikum Münster, Westfälische Wilhelms-Universität, Münster, ${ }^{2}$ Clinical Research Immunology and Dermatology, Novartis Pharma GmbH, Nürnberg, Germany, ${ }^{3}$ Novartis Pharma AG, Basel, Switzerland; ${ }^{4}$ Novartis Pharmaceuticals Corporation, New Jersey, USA

Background: Secukinumab (AIN457), a fully human anti-interleukin-17A monoclonal antibody, has demonstrated a significant clinically meaningful efficacy on signs and symptoms, structure and function in adults with ankylosing spondylitis $(\mathrm{AS})^{1}$ and psoriatic arthritis $(\mathrm{PsA})^{2}$, both approved indications. These data support the proposed study in children with enthesitis-related arthritis (ERA) and juvenile psoriatic arthritis (JPsA).

Objectives: This phase 3 study will investigate the efficacy and safety of secukinumab in children $\geq 2$ to $<18$ years with active JPsA or ERA. The primary objective is to demonstrate that the time to flare in a double-blind placebo control treatment withdrawal part of the trial is longer with secukinumab than placebo.

Methods: Eighty biologic-naïve children with active ERA or JPsA (active: $\geq 3$ active joints and $>1$ site of enthesitis at baseline or documented by history) will enrol into treatment period 1 and receive weekly open label s.c. secukinumab 75 or $150 \mathrm{mg}$, based on their body weight ( $<50 \mathrm{~kg}$ or $\geq 50 \mathrm{~kg}$ ) to maintain secukinumab blood levels equivalent to the adult $150 \mathrm{mg}$ dose, for the first month then every 4 weeks thereafter. At week 12, responders (minimum JIA ACR Pedi 30 response) enter treatment period 2 and will be randomised to receive secukinumab or a matching placebo every 4 weeks. Patients enter treatment period 3 if they experience a disease flare or when the treatment period 2 closes for the entire study because the target number of flares has been reached. Upon entering treatment period 3, patients receive open-label secukinumab every 4 weeks until week 100 and then followed until week 112.

Results: The primary efficacy endpoint will be time to flare in treatment period 2 . Key secondary endpoints include JIA Pedi ACR 30/50/70/90/100 response rate, total dactylitis and enthesitis counts at week 12 . Safety and tolerability will be assessed throughout the study.

Conclusions: The efficacy of Secukinumab in the approved adult indications of PsA and AS support the current study design to evaluate the efficacy and safety of secukinumab treatment in children with active JPsA or ERA. The primary efficacy endpoint will be time to flare in treatment period 2. Key secondary endpoints include JIA Pedi ACR 30/50/70/90/100 response rate, total dactylitis and enthesitis counts at week 12 . Safety and tolerability will be assessed throughout the study.

\section{REFERENCES:}

[1] Baeten D, et al. Lancet. 2013;382(9906):1705-13

[] 2Mclnnes

IB, et al. Lancet. 2015;386(9999):1137-46

Acknowledgements: This research was funded by Novartis Pharma AG, Basel, Switzerland

Disclosure of Interest: D. Foell Consultant for: Novartis Pharma GmbH, Speakers bureau: Novartis Pharma GmbH, J. Veit Employee of: Novartis Pharma GmbH, E. Ilsley Employee of: Novartis Pharma AG, K. Abrams Shareholder of: Novartis Pharmaceuticals Corporation, Employee of: Novartis Pharmaceuticals Corporation

DOI: 10.1136/annrheumdis-2018-eular.2097

\section{AB1090 ANALYSIS OF A COHORT OF PATIENTS ATTENDING A COMBINED OPHTHALMOLOGY- RHEUMATOLOGY CLINIC IN A TERTIARY REFERRAL CENTREIN EGYPT}

E. Abd El Latif. soliman Mahmoud Street, cleopatra, Alexandria, faculty of medicine, alexandria university, Alexandria, Egypt

Background: Paediatric rheumatologic diseases may have sight-threatening ocular complications including uveitis, scleritis, and retinopathy. Conversely, children presenting with uveitis, scleritis, episcleritis, or optic neuritis may have an underlying rheumatologic disease. Combined ophthalmology-rheumatology clinics can facilitate the comprehensive management of these patients.

Objectives: To describe the demographic characteristics, paediatric rheumatologic diseases distribution, paediatric ocular manifestations distribution, and active treatments in a combined ophthalmology- rheumatology clinic in a tertiary referral centre in Egypt. 